\title{
Cobalt Substituted for Rhodium in an Experimental NO Reduction Catalyst
}

\author{
Paul S. Dimick ${ }^{*}$ and Charles E. Lyman ${ }^{* *}$ \\ *Department of Chemical Engineering, Lehigh University, Bethlehem, PA 18015 \\ *** Department of Materials Science and Engineering, Lehigh University, Bethlehem, PA 18015
}

The effectiveness of supported bimetallic catalysts depends on the surface structure and composition of the active phase, which is typically present as nanoparticles. Bimetallic nanoparticles that perform better than either metal component alone are termed synergistic. The ideal nanoparticle surface microstructure for achieving synergy in a Pt-Rh catalyst for $\mathrm{NO}$ reduction with $\mathrm{H}_{2}$ as been proposed: single atoms of Rh surrounded by $\mathrm{Pt}$ [1]. By applying our understanding of how to form and tailor bimetallic nanoparticles, we designed and synthesized a synergistic Pt-Co catalyst by mimicking the microstructure of the synergistic Pt-Rh catalyst and replacing Rh with Co [2]. The Pt-Co particles were formed and tailored by applying time-temperature-atmosphere treatments to sequentially impregnated metal salt precursors. The Pt-Co alloy nanoparticles thus formed were synergistic in activity and selectivity, both with and without calcining after the addition of the Pt component (Figure 1). While both preparation routes produced catalysts with similar activity, the uncalcined catalyst produced $4 x$ more $\mathrm{N}_{2}$ compared to $\mathrm{N}_{2} \mathrm{O}+\mathrm{NH}_{3}$ than $\mathrm{Pt} / \gamma-\mathrm{Al}_{2} \mathrm{O}_{3}$ and the calcined catalyst produced 2.5x more $\mathrm{N}_{2}$ compared to $\mathrm{N}_{2} \mathrm{O}+\mathrm{NH}_{3}$ than $\mathrm{Pt} / \gamma-\mathrm{Al}_{2} \mathrm{O}_{3}$. Synergistic performance was not observed until the bimetallic catalysts were conditioned exposure to reaction conditions at $250^{\circ} \mathrm{C}$.

Since the catalysts were prepared by the decomposition of metal-salt precursors, a distribution of nanoparticles in both size and composition may be present on the catalyst support. Since most of the observed nanoparticles are less than $5 \mathrm{~nm}$, aberration-corrected scanning transmission electron microscopy was used to identify differences in nanoparticle size and structure. Figure 2 shows a HAADF image of a synergistic $\mathrm{Pt}(98 \mathrm{wt} \%) \mathrm{C}-\mathrm{Co}(2 \mathrm{wt} \%) / \gamma-\mathrm{Al}_{2} \mathrm{O}_{3}$ catalyst acquired on a JEOL JEM 2200FS microscope. This image shows particles of various shapes in the size range 1-5 nm. The inset image shows Pt atomic columns in a linear raft-like nanoparticle. While the majority of nanoparticles were nearly spherical, several non-spherical nanoparticles with sizes less than $2 \mathrm{~nm}$ were observed.

The hypothetical ideal nanoparticle microstructure above requires that the particles are single-phase Pt-Co alloys. X-ray spectrometry in the JEOL JEM 2200FS showed that nanoparticles in a Pt(95\%)$\mathrm{Co}(5 \%) / \gamma-\mathrm{Al}_{2} \mathrm{O}_{3}$ catalyst do contain both $\mathrm{Pt}$ and $\mathrm{Co}$ (Figure 3 ). The Co x-ray signal from an individual nanoparticle containing $5 \%$ Co is exceedingly weak because only a few Co atoms exist in each particle. The spectrum shown in Figure 3 was produced by summing spectra from 40 individual particles to obtain a statistically significant Co peak, according to the criteria defined by Williams and Carter $[3,4]$.

References:

[1] P.S. Dimick et al., Appl. Catal. B: Environ. 89 (2009) 1.

[2] P.S. Dimick, R.G. Herman, and C.E. Lyman, Catal. Lett, In Press, DOI: DOI 10.1007/s10562010-0273-8.

[3] D.B. Williams and C.B. Carter, Transmission Electron Microscopy. Springer, New York, 1996. [4] Funding provided by the National Science Foundation (Grant DMR-0506705). 

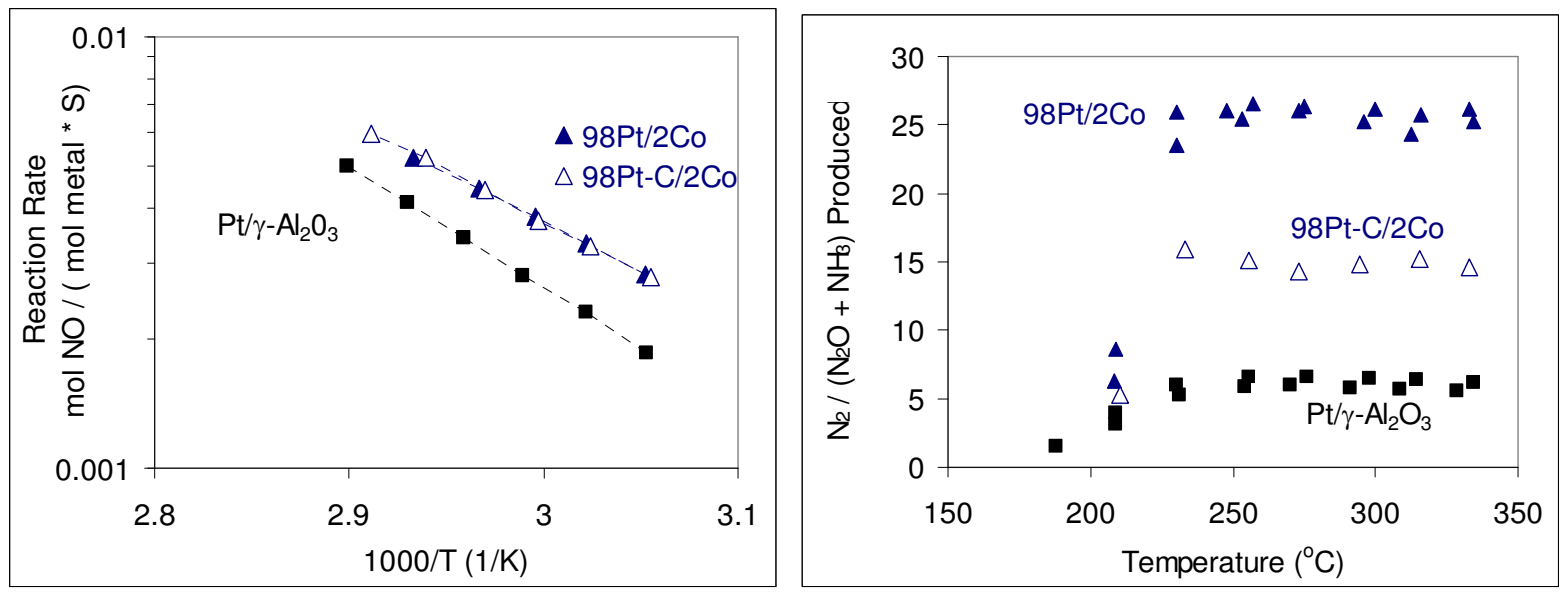

FIG. 1. Activity (left) and selectivity to $\mathrm{N}_{2}$ expressed as the desired to undesired product ratio (right) of the synergistic Pt-Co catalysts.

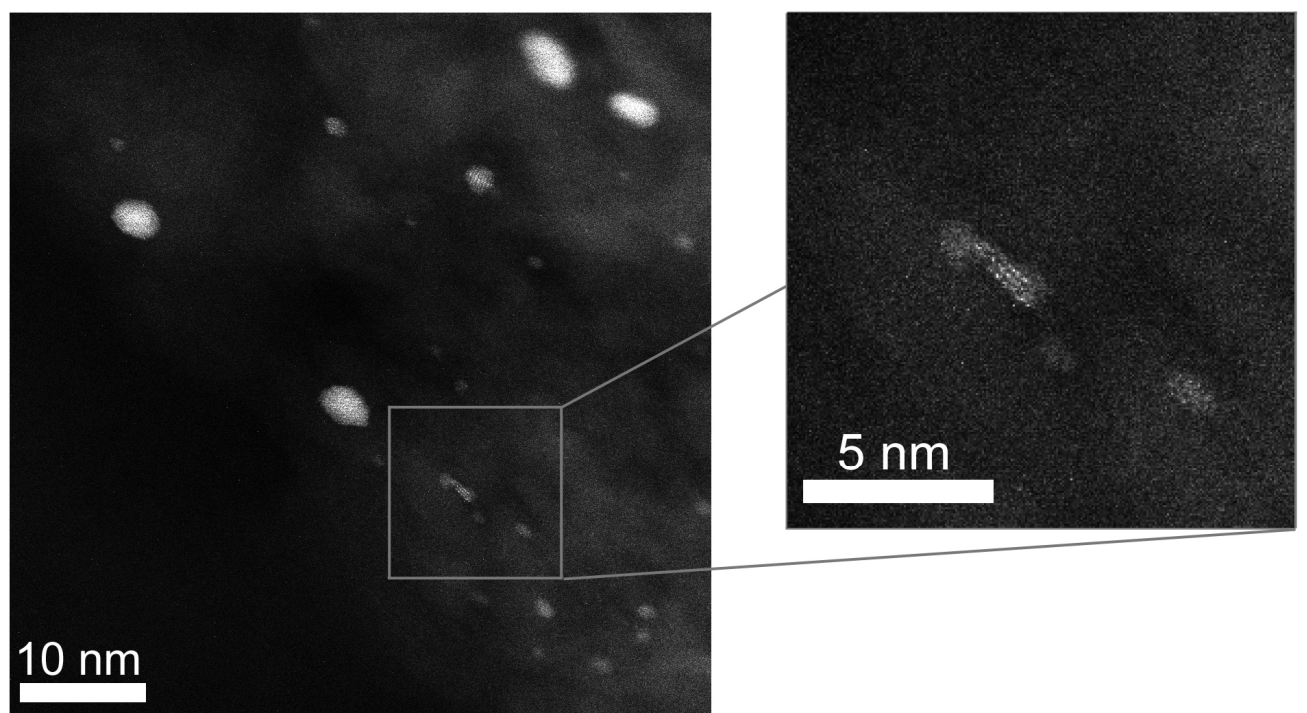

FIG 2. High-Angle Annular Dark Field (HAADF) electron micrograph of the Pt(98wt\%)C$\mathrm{Co}(2 \mathrm{wt} \%) / \gamma-\mathrm{Al}_{2} \mathrm{O}_{3}$ catalyst

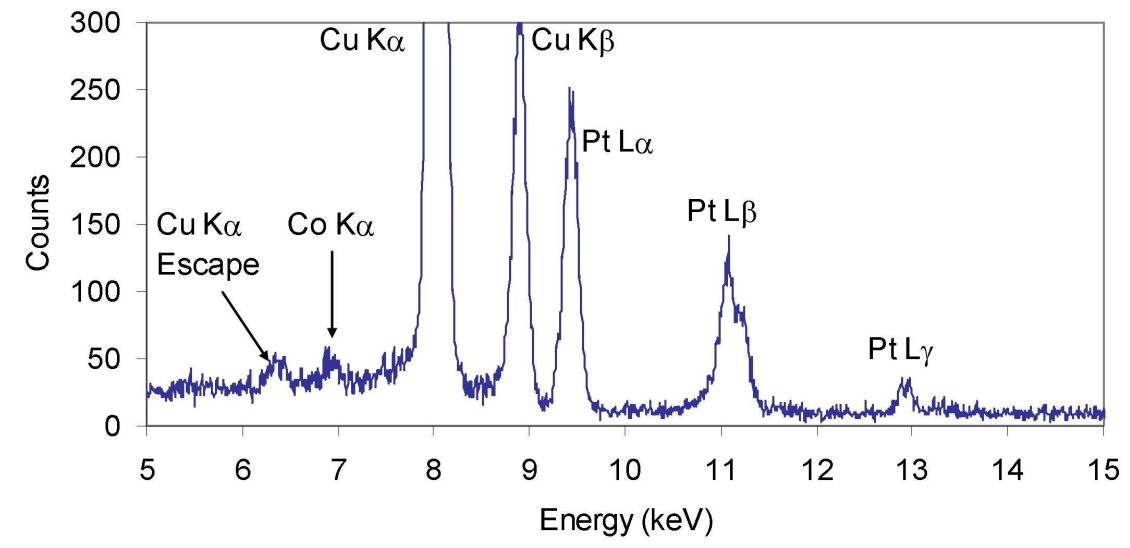

FIG. 3. Summed XEDS spectra from 40 individual nanoparticles of $\mathrm{Pt}(95 \%) \mathrm{C}-\mathrm{Co}(5 \%) / \gamma-\mathrm{Al}_{2} \mathrm{O}_{3}$. 